\title{
Alocação de fotoassimilados em folhas e frutos de cafeeiro cultivado em duas altitudes
}

\author{
Bruno Galvêas Laviola(1), Herminia Emilia Prieto Martinez(2), Luiz Carlos Chamhum Salomão(2), \\ Cosme Damião Cruz $^{(3)}$, Sebastião Marcos Mendonça(4) e Ana Paula Neto ${ }^{(2)}$
}

\begin{abstract}
(1)Embrapa Agroenergia, Parque Estação Biológica-PqEB s/no, CEP 70770-901 Brasília, DF. E-mail: bruno.laviola@embrapa.br (2)Universidade Federal de Viçosa (UFV), Dep. de Fitotecnia, Av. P.H. Rolfs, s/no, CEP 36570-000 Viçosa, MG. E-mail: herminia@ufv.br, Isalomao@ufv.br, anap_neto@yahoo.com.br (3)UFV, Dep. de Biologia Geral. E-mail: cdcruz@ufv.br (4)Centro de Pesquisas Cafeeiras Eloy Carlos Heringer, Rod. BR 262, Km 39,4, CEP 36900-000 Manhuaçu, MG. E-mail: sebastiao.mendonca@heringer.com.br
\end{abstract}

Resumo - O objetivo deste trabalho foi avaliar a alocação de fotoassimilados em frutos e folhas de cafeeiro arábico, da antese à maturação, em duas altitudes. O experimento foi constituído da variedade de cafeeiro (Coffea arábica L.) Catuaí IAC-44, cultivada a 720 e 950 m de altitude, no Município de Martins Soares, MG. O delineamento experimental foi inteiramente ao acaso, com três repetições, em um esquema de parcela subdividida no tempo. $\mathrm{Na}$ altitude de 720 m o acúmulo de amido, açúcares solúveis totais, açúcares redutores e açúcares não-redutores em frutos de cafeeiro deu-se em menor tempo. O acúmulo de amido na altitude de $720 \mathrm{~m}$ antecedeu o acúmulo de amido na altitude de $950 \mathrm{~m}$, e os frutos apresentaram maior porcentagem de acúmulo relativo desse composto no estádio de expansão rápida. Neste estádio, a concentração de carboidratos em folhas dos $3^{\circ}$ e $4^{\circ}$ pares decresceu bruscamente, indicando ser este o período mais crítico para a concentração de carboidratos em folhas. A altitude influencia a alocação de fotoassimilados em frutos e a variação da concentração de carboidratos em folhas de cafeeiro.

Termos para indexação: Coffea arabica, fisiologia vegetal, carboidratos, temperatura.

\section{Assimilates allocation in fruits and leaves of coffee plants cultivated in two altitudes}

\begin{abstract}
The objective of this work was to evaluate the allocation of carbohydrates in fruits of Arabic coffee plant during the period comprised among the anthesis and maturation in two different altitudes, as well as, the variation in its content in leaves of these productive branches. The experiment was constituted of the coffee plant variety (Coffea arabica L.) Catuaí IAC-44 cultivated at 720 and $950 \mathrm{~m}$ above the sea level in Martins Soares, Minas Gerais State, Brazil. The experimental design was completely randomized with three repetitions using splitplot in time scheme. The altitude of $720 \mathrm{~m}$ contributed to an acceleration in the accumulation of starch, total soluble sugar, reducing sugar and non-reducing sugar in coffee plant fruits. The accumulation of starch in the altitude of $720 \mathrm{~m}$ preceded the accumulation in the altitude of $950 \mathrm{~m}$, presenting larger earning percentage in the fruit fast expansion stadium. In this stadium, carbohydrate concentrations in leaves in the $3^{\text {rd }}$ and $4^{\text {th }}$ leave pairs of productive branches decreased abruptly indicating that this is the most critic period for the carbohydrate concentrations in leaves. Altitude influenced the extension of the cycle, as well as the assimilate accumulation by fruits and that variation in coffee plant leaves.
\end{abstract}

Index terms: Coffea arabica, plant physiology, carbohydrates, temperature.

\section{Introdução}

O cafeeiro, sob condições de cultivo a pleno sol, é caracterizado como planta que apresenta bienalidade de produção, com significativa alternância de produtividade ao longo dos anos. A bienalidade de produção parece estar associada à incapacidade de a planta de cafeeiro sintetizar, em anos de alta produção de frutos, fotoassimilados suficientes para suprir as demandas da frutificação e, paralelamente, as necessidades para o crescimento dos órgãos vegetativos (Rena \& Maestri, 1985; Carvalho et al., 1993).

Os frutos são os drenos preferenciais de fotoassimilados durante o período reprodutivo. Rena et al. (1996) relatam elevado grau de dependência do estado nutricional da planta e da relação funcional entre folha e fruto. A dependência do cafeeiro dessa relação funcional deve-se à característica da espécie de não regular a 
carga de frutos que, em grande quantidade, em comparação à área foliar, provoca distúrbios fisiológicos, como a seca de ponteiros (Rena \& Carvalho, 2003).

Os principais carboidratos, não-estruturais, acumulados em folhas e frutos de cafeeiro são o amido e os açúcares solúveis redutores e não-redutores. Entre os açúcares redutores, os principais são a glicose e frutose, enquanto o principal açúcar não-redutor é a sacarose, mobilizado nos processos de transporte na direção fonte/dreno (Taiz \& Zeiger, 2004).

A compreensão da alocação de fotoassimilados entre folhas e frutos de cafeeiro pode ser importante para se identificar os períodos de maior demanda de fotoassimilados durante o estádio reprodutivo (Rena \& Maestri, 1985). Com essa informação, seria possível maximizar, por meio de práticas culturais, a produção de fotoassimilados nos períodos mais críticos, de forma que a planta viesse a produzir carboidratos em quantidades suficientes para o desenvolvimento dos frutos e para manutenção do crescimento vegetativo, reduzindo a bienalidade de produção (Carvalho et al., 1993; Laviola et al., 2007).

Em regiões de maior altitude, observa-se que o cafeeiro leva mais tempo para completar o seu ciclo (Matiello et al., 2005). Essa informação indica que o pico de exigência em fotoassimilados do cafeeiro cultivado em regiões de maiores altitudes é mais tardio que em regiões de menores altitudes.

O objetivo deste trabalho foi determinar a alocação de fotoassimilados em frutos e folhas de cafeeiro arábico, da antese à maturação, em lavouras cultivadas em duas altitudes.

\section{Material e Métodos}

O experimento foi conduzido de setembro de 2005 a julho de 2006, no Centro de Pesquisas Cafeeiras Eloy Carlos Heringer (Cepec), localizado no Município de Martins Soares, MG. O experimento consistiu de duas áreas experimentais, nas altitudes de $720 \mathrm{~m} \mathrm{e} 950 \mathrm{~m}$, cultivadas com a variedade de cafeeiro (Coffea arabica L.) Catuaí IAC-44 com idade de 4 anos (recepada em 2002) e de 11 anos, espaçamento $2 \times 1$ e $1,7 \times 0,7 \mathrm{~m}$ e produtividade média de 1.260 e $2.040 \mathrm{~kg} \mathrm{ha}^{-1}$, respectivamente. Na ocasião da implantação do experimento, as plantas referentes à altitude de $720 \mathrm{~m}$, recepadas em 2002, apresentavam formato de copa semelhante às plantas da altitude de $950 \mathrm{~m}$.
O clima do local, de acordo com a classificação de Köppen, é mesotérmico com verões úmidos (Cwa). As temperaturas máximas $\left(\mathrm{T}_{\text {máx }}\right)$ e mínimas $\left(\mathrm{T}_{\text {mín }}\right)$ e umidade relativa (UR) avaliadas nas altitudes de 720 e $950 \mathrm{~m}$ estão apresentadas na Tabela 1 . A precipitação mensal (mm) durante o ano agrícola 2005/2006, no local do experimento, foi: $12 \mathrm{em}$ agosto, 168,4 em setembro, 59,3 em outubro, 353,5 em novembro, 278,2 em dezembro, 7 em janeiro, $131 \mathrm{em}$ fevereiro, 256,5 em março, 121,8 em abril, 31 em maio, 8 em junho e 13,8 em julho.

Em agosto de 2005, foi realizada a amostragem do solo, coletando-se em cada altitude 15 subamostras, sendo 5 subamostras em cada parcela, para formar uma amostra composta. As características químicas do solo da área experimental foram: matéria orgânica, 3,58 e 4,61 dag $\mathrm{kg}^{-1} ; \mathrm{pH}$ em água, 6,1 e 5,2; $\mathrm{P}$ (Mehlich), 27 e $7,5 \mathrm{mg} \mathrm{dm}^{-3} ; \mathrm{K}, 132$ e $116 \mathrm{mg} \mathrm{dm}^{-3} ; \mathrm{Ca}, 4,2 \mathrm{e}$ $2,4 \mathrm{cmol}_{\mathrm{c}} \mathrm{dm}^{-3} ; \mathrm{Mg}, 0,9$ e $0,3 \mathrm{cmol}_{\mathrm{c}} \mathrm{dm}^{-3}$; CTC, 9,73 e $11,25 \mathrm{cmol}_{\mathrm{c}} \mathrm{dm}^{-3} ; \mathrm{S}, 22,4$ e $24,1 \mathrm{mg} \mathrm{dm}^{-3} ; \mathrm{V}, 56$ e $27 \%$; $\mathrm{Zn}, 27,1$ e 13,5 mg dm${ }^{-3}$; Cu, 3,9 e 3,1 $\mathrm{mg} \mathrm{dm}^{-3}$; B, 1,54 e $1,54 \mathrm{mg} \mathrm{dm}^{-3}$. As classes texturais dos solos nas altitudes de 720 e $950 \mathrm{~m}$ foram argilo-arenoso e francoargilo-arenoso, respectivamente. Os solos da área experimental foram classificados como Latossolo Vermelho-Amarelo distrófico. Na altitude de $720 \mathrm{~m}$, a adubação do solo foi de $390 \mathrm{~kg} \mathrm{ha}^{-1}$ de N e $200 \mathrm{~kg} \mathrm{ha}^{-1}$ de $\mathrm{K}_{2} \mathrm{O}$ e na de $950 \mathrm{~m}, 370 \mathrm{~kg} \mathrm{ha}^{-1}$ de $\mathrm{Ne} 70 \mathrm{~kg} \mathrm{ha}^{-1}$ de $\mathrm{K}_{2} \mathrm{O}$, utilizando-se sulfato de amônio como fonte de $\mathrm{Ne}$ cloreto de potássio como fonte de $\mathrm{K}$.

Tabela 1. Temperatura mínima $\left(\mathrm{T}_{\text {mín }},{ }^{\circ} \mathrm{C}\right)$, temperatura máxima $\left(\mathrm{T}_{\text {máx }},{ }^{\circ} \mathrm{C}\right)$ e umidade relativa (UR, \%) em duas altitudes de cultivo do cafeeiro.

\begin{tabular}{|c|c|c|c|c|c|c|}
\hline \multirow[t]{2}{*}{ Datas } & \multicolumn{2}{|c|}{$\mathrm{T}_{\operatorname{mín}}$} & \multicolumn{2}{|c|}{$\mathrm{T}_{\text {máx }}$} & \multicolumn{2}{|c|}{ UR } \\
\hline & $720 \mathrm{~m}$ & $950 \mathrm{~m}$ & $720 \mathrm{~m}$ & $950 \mathrm{~m}$ & $720 \mathrm{~m}$ & $950 \mathrm{~m}$ \\
\hline $17 / 2 / 2006$ & 35 & 31 & 21 & 20 & 55 & 77 \\
\hline $23 / 2 / 2006$ & 37 & 33 & 20 & 21 & 71 & 81 \\
\hline $3 / 3 / 2006$ & 29 & 23 & 21 & 20 & 83 & 96 \\
\hline $9 / 3 / 2006$ & 35 & 31 & 22 & 22 & 66 & 75 \\
\hline $17 / 3 / 2006$ & 27 & 24 & 19 & 20 & 76 & 88 \\
\hline $30 / 3 / 2006$ & 35 & 32 & 17 & 21 & 77 & 92 \\
\hline $6 / 4 / 2006$ & 32 & 27 & 15 & 22 & 83 & 91 \\
\hline $12 / 4 / 2006$ & 41 & 32 & 17 & 22 & 76 & 88 \\
\hline $20 / 4 / 2006$ & 23 & 20 & 15 & 15 & 75 & 86 \\
\hline $28 / 4 / 2006$ & 32 & 26 & 18 & 17 & 90 & 100 \\
\hline $4 / 5 / 2006$ & 30 & 28 & 18 & 21 & 83 & 91 \\
\hline $17 / 5 / 2006$ & 24 & 20 & 10 & 10 & 69 & 69 \\
\hline $23 / 5 / 2006$ & 29 & 27 & 12 & 17 & 62 & 70 \\
\hline $31 / 5 / 2006$ & 29 & 28 & 15 & 12 & 68 & 83 \\
\hline $8 / 6 / 2006$ & 26 & 23 & 8 & 13 & 63 & 61 \\
\hline $13 / 6 / 2006$ & 28 & 30 & 15 & 10 & 74 & 55 \\
\hline $20 / 6 / 2006$ & 26 & 24 & 12 & 14 & 61 & 72 \\
\hline $28 / 6 / 2006$ & 26 & 26 & 17 & 15 & 79 & 95 \\
\hline
\end{tabular}


A recomendação de adubação foi realizada de acordo com a fertilidade do solo e com a carga pendente de frutos (Guimarães et al., 1999). O enxofre foi fornecido como elemento acompanhante do fertilizante nitrogenado. Os micronutrientes $\mathrm{Zn}, \mathrm{B}$ e $\mathrm{Cu}$ foram supridos por meio de três aplicações foliares anuais aos 8,72 e 103 dias após a antese (19/10/2005, 22/12/2005 e 22/1/2006), utilizando-se sulfato de zinco, ácido bórico, hidróxido de cobre e cloreto de potássio, como adjuvante, na concentração de $4 \mathrm{~g} \mathrm{~L}^{-1}$ de cada adubo.

$\mathrm{O}$ delineamento experimental foi inteiramente ao acaso em um esquema de parcelas subdividas no tempo, com duas parcelas (altitudes), 12 subparcelas (datas de amostragens) e três repetições. Em cada altitude, foram selecionadas três parcelas com 20 plantas dispostas em quatro fileiras, que constituíram as parcelas experimentais.

O período amostral iniciou-se após 11/10/2005, quando houve antese (florada principal) e, a partir dessa data, efetuaram-se coletas periódicas de folhas e frutos durante o desenvolvimento reprodutivo do cafeeiro: aos 34 (14/11/2005), 52 (2/12/2005), 65 (15/12/2005), 85 (4/1/2006), $100(19 / 1 / 2006), 114(12 / 2 / 2006)$, 134 (22/2/2006), 161 (21/3/2006), 190 (19/4/2006), 217 (16/5/2006), 239 (8/6/2006) e 266 (4/7/2006) dias após a antese (DAA). Na análise de carboidratos, foram selecionadas amostras referentes aos $34,52,100,114$, 161, 217, 266 DAA, e, na análise de amido em folhas, foram perdidas as amostras referentes aos 34 DAA.

Foram colhidos frutos aleatoriamente na parcela, em ramos pertencentes ao terço médio da planta para avaliação da produção de matéria seca. Para as demais avaliações, foram colhidos frutos e coletadas folhas

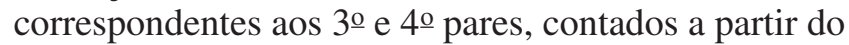
ápice de ramos com frutos, também situados no terço médio da planta. A cada amostragem foram coletados $1 \mathrm{a} 2 \mathrm{~g}$ de frutos por parcela, e sete discos de folhas por parcela, aproximadamente $500 \mathrm{mg}$ de matéria fresca, os quais foram retirados com auxílio de um furador de rolhas de $1,9 \mathrm{~cm}$ de diâmetro. Essas coletas foram realizadas no período da manhã, no intervalo das 8 às $10 \mathrm{~h}$. Após as coletas, os frutos e os discos foliares foram congelados em nitrogênio líquido e, posteriormente, armazenados em freezer a $-60^{\circ} \mathrm{C}$.

Antes de as análises serem iniciadas, parte das amostras de frutos foram transferidas para uma estufa de circulação forçada de ar, a $70^{\circ} \mathrm{C}$, por 72 horas, para determinação de matéria seca. Para a análise de açúcares solúveis totais (AST) e açúcares redutores (AR), as amostras previamente congeladas foram transferidas para almofariz e maceradas, adicionandose etanol $80 \%$ fervente e areia lavada. O produto da maceração foi transferido quantitativamente para tubos de plástico e centrifugado a $3.300 \mathrm{~g}$, por $10 \mathrm{~min}$. O precipitado foi lavado com $2,5 \mathrm{~mL}$ de etanol $80 \%$, por mais três vezes, e centrifugado, e o volume dos sobrenadantes combinados foi completado para $25 \mathrm{~mL}$. Dos $25 \mathrm{~mL}$ de solução etanólica, foram retirados $10 \mathrm{~mL}$ e evaporados até secura, em evaporador rotativo a vácuo, a $45^{\circ} \mathrm{C}$. O resíduo da evaporação foi ressuspendido em $5 \mathrm{~mL}$ de água destilada e armazenado a $-20^{\circ} \mathrm{C}$, até o momento das análises. Os açúcares solúveis totais foram quantificados por meio da reação com antrona, segundo método preconizado por McCready et al. (1950), e os açúcares redutores (AR) por meio da técnica de Nelson (1944) e Somogy (1952). Os açúcares não-redutores (ANR) foram obtidos pela diferença entre AST e AR.

Para a extração do amido, o resíduo das extrações alcoólicas foi tratado com $5,75 \mathrm{~mL}$ de ácido perclórico $30 \%$, por três vezes, permitindo-se tempos de reação, de 20, 30 e 20 min, para cada extração, respectivamente. Transcorrido o tempo de reação, foram acrescentados ao extrato $6 \mathrm{~mL}$ de água destilada e, em seguida, o material foi centrifugado a $3.300 \mathrm{~g}$, por $10 \mathrm{~min}$. Os sobrenadantes obtidos por meio desse processo foram combinados e completados com água destilada para um volume de $50 \mathrm{~mL}$. A quantificação do amido foi realizada por meio da reação com antrona de acordo com o protocolo descrito por Hodge \& Hodfreiter (1962).

$\mathrm{O}$ acúmulo dos carboidratos por fruto (mg por fruto) foi calculado pela equação: Acúmulo $=(\mathrm{MS}$ do fruto $(\mathrm{mg})$ $\mathrm{x}$ concentração de carboidratos (\%))/100.

Os dados obtidos foram submetidos à análise de variância e regressão. A fim de explicar fisiologicamente o acúmulo de carboidratos em frutos, utilizaram-se modelos de regressões não-lineares sigmoidais com $3 \mathrm{e}$ 4 parâmetros. A escolha dos modelos não-lineares foi feita de acordo com a porcentagem da variância explicada $\left(\mathrm{R}^{2}\right)$ e a melhor representação do fenômeno:

$$
\begin{aligned}
& \hat{y}=\frac{a}{1+\exp -\left(\frac{x-x_{0}}{b}\right)} \\
& \hat{y}=y_{0}+\frac{a}{1+\exp -\left(\frac{x-x_{0}}{b}\right)}
\end{aligned}
$$


em que, ŷ é acúmulo de carboidrato; a é o ponto máximo da curva $\left(\mathrm{y}_{\text {máx }}-\mathrm{y}_{\text {mín }}\right)$; b é o parâmetro de ajuste; $\mathrm{x}_{0}$ é o ponto de inflexão e $y_{0}$ é o ponto de mínimo da curva.

O ponto de inflexão foi correspondente ao momento em que ocorreram as taxas máximas de acúmulo de matéria seca e carboidratos em frutos. A taxa máxima de acúmulo diário (TMAD, $\mathrm{mg} \mathrm{dia}^{-1}$ ) foi determinada pelo acúmulo de matéria seca e carboidratos no ponto de inflexão menos o acúmulo do dia anterior.

Os pontos de curvatura mínima $\left(\mathrm{PC}_{\mathrm{mín}}\right)$ e máxima $\left(\mathrm{PC}_{\text {máx }}\right)$ foram calculados conforme método citado por Venegas et al. (1998), utilizando-se os parâmetros das equações não-lineares:

$\mathrm{PC}_{\text {mín }}=\mathrm{x}_{0}-2 \mathrm{~b}$ e $\mathrm{PC}_{\text {máx }}=\mathrm{x}_{0}+2 \mathrm{~b}$

$\mathrm{O} \mathrm{PC}_{\text {mín }}$ (dias) indica o momento, na curva de acúmulo, em que se iniciam ganhos expressivos no acúmulo de nutrientes. Já o $\mathrm{PC}_{\text {máx }}$ (dias) indica o momento em que o acúmulo dos nutrientes começa a se estabilizar. Esses parâmetros foram, também, utilizados para delimitar os estádios de formação dos frutos de cafeeiro.

$\mathrm{O}$ acúmulo relativo $\left(\mathrm{AR}_{\mathrm{e}}\right)$ foi calculado de acordo com as diferenças entre o mínimo e o máximo acúmulo em cada estádio de formação do fruto, sendo os valores em porcentagem obtidos em relação ao acúmulo final alcançado, pelas equações:

$A R_{e}=A_{F}-A_{I}$ e $A R_{e}(\%)=100\left(A R_{e} / A T\right)$, em que: $\mathrm{AR}_{\mathrm{e}}$ é o acúmulo relativo no estádio de formação do fruto; $A_{F}$ e $A_{I}$ são o acúmulo no final e início do estádio; $\mathrm{AR}_{\mathrm{e}}$ é o acúmulo relativo expresso em porcentagem e AT é o acúmulo alcançado aos 266 DAA.

\section{Resultados e Discussão}

A extensão do ciclo do cafeeiro e a duração dos estádios reprodutivos foram influenciadas pela altitude de cultivo da lavoura (Figura 1 e Tabela 2). Na altitude de $720 \mathrm{~m}$, observou-se que o fruto necessitou de 211 dias (10/5/2005) para sua formação, ao passo que, a $950 \mathrm{~m}$, a formação do fruto foi até 262 dias após a antese (DAA) (30/6/2005).

É provável que a ocorrência de menores temperaturas máximas tenha influenciado as reações enzimáticas e o transporte de fotoassimilados (Larcher, 2000), ampliando o tempo de formação do fruto do cafeeiro. A duração do ciclo nas duas altitudes foi maior, comparada à observada por Laviola (2007), o qual verificou um ciclo de 224 dias em Viçosa, MG. Além disso, neste mesmo trabalho, não houve efeitos significativos de variedades e de níveis de adubação (baixo, médio e alto) sobre o acúmulo de matéria seca e macronutrientes em frutos.
Os frutos passaram por cinco estádios distintos de formação (Rena et al., 2001): chumbinho (720 m, 0-65 DAA; $950 \mathrm{~m}$, 0-61 DAA), expansão rápida (720 m, 65-109 DAA; 950 m, 61-98 DAA), crescimento suspenso (720 m, 109-114 DAA; 950 m, 98-114 DAA), granação (720 m, 114-211 DAA; 950 m, 114-262 DAA) e maturação (720 m, 211-266 DAA; 950 m, 262-266 DAA). Ficou estabelecido como maturação o período compreendido entre a estabilização no acúmulo de matéria seca nos frutos $\left(\mathrm{PC}_{\text {máx }}\right.$, Tabela 2$)$ e a última amostragem, embora as mudanças de coloração da casca correspondente à maturação tenham se iniciado um pouco antes. Portanto, na altitude de 720 m, a maturação dos frutos finalizou antes dos 266 DAA. De acordo com Camargo \& Camargo (2001), os estádios de formação dos frutos são bem definidos, porém, podem adiantar-se ou atrasar-se de acordo com o clima e a região, até mesmo a altitude. Cada estádio de formação possui funções fisiológicas e metabólicas próprias, essenciais à formação final da semente de café (Cannel, 1971; Coombe, 1976).

No estádio de chumbinho, os frutos apresentaram acúmulo pouco expressivo de matéria seca, amido, açúcares solúveis totais (AST), açúcares redutores (AR) e açúcares não-redutores (ANR) (Figura 1 e Tabela 3). De acordo com Leon \& Fournier (1962) e Cannel (1971), os frutos de cafeeiro, neste estádio, apresentam elevada taxa de divisão celular e de respiração celular, o que impossibilitaria o acúmulo de compostos de reserva (amido), bem como de AR e ANR.

O estádio de expansão rápida (Figura 1) se caracteriza, principalmente, por rápido alongamento das células dos frutos, atingindo, no final do estádio, cerca de $80 \%$ do tamanho final do fruto (Cannel, 1971; Rena et al., 2001). No estádio de expansão rápida, observou-se acúmulo expressivo de matéria seca nos frutos e, na altitude de $720 \mathrm{~m}$ ocorreu maior acúmulo relativo comparado à altitude de $950 \mathrm{~m}$ (Tabela 3).

A ascensão no acúmulo de amido $\left(\mathrm{PC}_{\mathrm{mín}}\right)$ ocorreu após o pico de acúmulo de matéria seca nos frutos ( $\mathrm{X}_{\mathrm{TMAD}}$ ) no estádio de expansão rápida, indicando que o aumento de matéria seca não está relacionado ao acúmulo de compostos de reserva (Tabela 2). Assim, o acúmulo de matéria seca nesse estádio esta relacionado, principalmente, à deposição de material de parede (Coombe, 1976), essencial para o processo de alongamento celular (Marenco \& Lopes, 2005). 

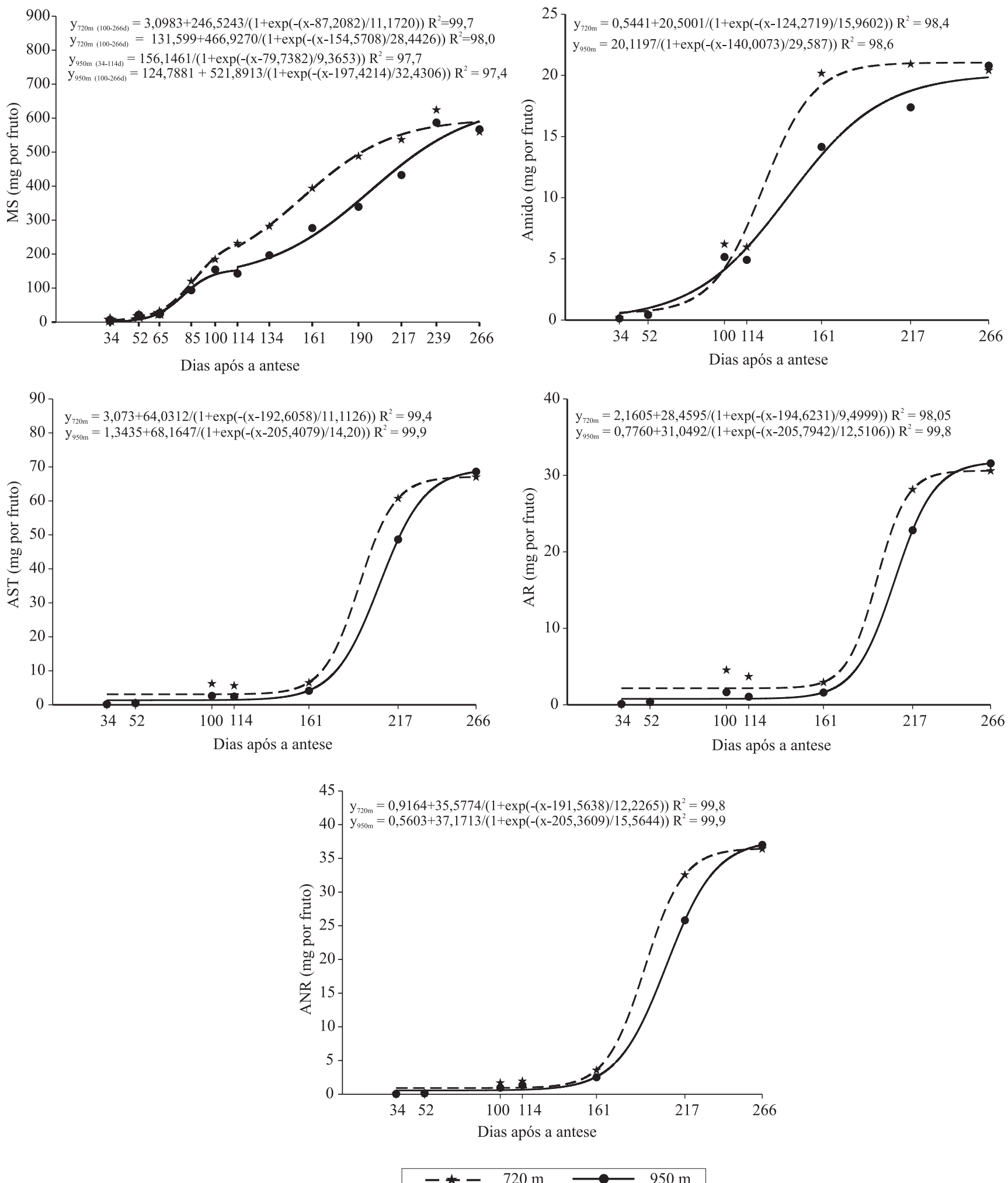

Figura 1. Acúmulo de matéria seca (MS), amido, açúcares solúveis totais (AST), açúcares redutores (AR), açúcares não-redutores (ANR) em frutos de cafeeiro implantado em duas altitudes, de acordo com o tempo decorrido após a antese. 
No estádio de expansão rápida, não se observou aumento de grande magnitude no acúmulo de AST, AR e ANR nos frutos de cafeeiro, assim como não foram observados efeitos da altitude (Figura 1 e Tabela 3). É possível que a maior parte dos fotoassimilados drenados para os frutos nesta época tenha sido convertida em polímeros de parede (Taiz \& Zeiger, 2004), impedindo que estes fossem acumulados nos frutos.

O ponto em que ocorreu a taxa máxima de acúmulo diário $\left(\mathrm{X}_{\mathrm{TMAD}}\right)$ de carboidratos foi no estádio de granação dos frutos, influenciado pela altitude de cultivo do cafeeiro (Tabela 2). Os $X_{\text {TMAD }}$ de amido, AST, AR e ANR apresentaram tendência de ser mais tardios na maior altitude de cultivo. Além disso, as taxas máximas de acúmulo diário (TMAD) também foram influenciadas pela altitude de cultivo, apresentando maiores valores na altitude de $720 \mathrm{~m}$. Os maiores valores de TMAD indicam que na altitude de $720 \mathrm{~m}$ a partição de carboidratos para os frutos de cafeeiro ocorreu em maior velocidade do que na altitude de $950 \mathrm{~m}$.

A síntese de amido e outros carboidratos em frutos de cafeeiro são dependentes, primeiramente, das enzimas de clivagem da sacarose, as quais também influenciam a velocidade de transporte no floema na direção fonte/dreno (Taiz \& Zeiger, 2004). Geromel et al. (2006) verificaram maior atividade da enzima sacarose sintase durante o desenvolvimento dos frutos de cafeeiro em meados do estádio de granação, aproximadamente aos 175 DAA. Outras enzimas relacionadas à hidrólise da sacarose em frutos de cafeeiro são as invertases, que, porém, apresentaram maior atividade na fase inicial de desenvolvimento do fruto. A atividade enzimática é influenciada pela temperatura (Larcher, 2000), por isso, é possível que as menores temperaturas máximas ocorridas na altitude de $950 \mathrm{~m}$ tenham influenciado a atividade das enzimas de clivagem da sacarose, diminuindo a velocidade de acúmulo de MS e carboidratos em frutos.

No estádio de granação, também chamado de enchimento do endosperma, a matéria seca é depositada, principalmente, nas sementes (Rena et al., 2001), sendo o amido um dos principais compostos de reserva (Giorgine \& Campos, 1992). O acúmulo de amido nos frutos cessou antes do final do estádio de granação, ou seja, as reservas das sementes foram acumuladas antes dos frutos completarem sua formação final (Tabela 2). De acordo com Puschmann (1975), o crescimento do endosperma, onde se encontra a maior parte do amido, é restringido pelo endocarpo lignificado antes da formação final do fruto. O subseqüente crescimento do fruto é devido à expansão do pericarpo.

$\mathrm{O}$ acúmulo de amido nos frutos na altitude de $720 \mathrm{~m}$ antecedeu o acúmulo deste composto na altitude de 950 m (Figura 1 e Tabela 2). Além disso, houve maior acúmulo relativo $\left(\mathrm{AR}_{\mathrm{e}}\right)$ de amido no estádio de expansão rápida a $720 \mathrm{~m}$, quando comparado ao que ocorreu a $950 \mathrm{~m}$ de altitude (Tabela 3 ). Ao contrário, no estádio de granação, foi verificado maior $\mathrm{AR}_{\mathrm{e}}$ de amido a $950 \mathrm{~m}$ em comparação ao obtido a $720 \mathrm{~m}$. Assim, parece haver compensação no acúmulo de amido entre os dois estádios. Se no estádio de expansão o acúmulo de amido é mais acelerado, no estádio de granação o acúmulo será em menor velocidade, e vice-versa.

Esses resultados indicam que o acúmulo de amido em frutos é mais precoce em altitudes menores. Desta forma, o enchimento de grãos é mais crítico em condições de menor altitude, já que a planta completa esse processo

Tabela 2. Ponto da taxa máxima de acúmulo diário ( $\mathrm{X}_{\mathrm{TMAD}}$, DAA), taxa máxima de acúmulo diária (TMAD, mg por fruto por dia) e ponto de curvatura mínima $\left(\mathrm{PC}_{\mathrm{mín}}\right.$, $\left.\mathrm{DAA}\right)$ e máxima $\left(\mathrm{PC}_{\text {máx }}, \mathrm{DAA}\right)$ de matéria seca e de carboidratos em frutos de cafeeiro implantado em duas altitudes.

\begin{tabular}{|c|c|c|c|c|c|c|}
\hline Variável $^{(1)}$ & Altitude (m) & Período (dias) & $\mathrm{X}_{\mathrm{TMAD}}$ (DAA) & TMAD & $\mathrm{PC}_{\min }(\mathrm{DAA})$ & $\mathrm{PC}_{\text {máx }}(\mathrm{DAA})$ \\
\hline \multirow[t]{4}{*}{ MS } & 720 & $34-114$ & 87 & 5,5110 & 65 & 109 \\
\hline & & $100-266$ & 154 & 4,1025 & 114 & 211 \\
\hline & 950 & 34-114 & 80 & 4,1665 & 61 & 98 \\
\hline & & $100-266$ & 197 & 4,0222 & 132 & 262 \\
\hline \multirow[t]{2}{*}{ Amido } & 720 & $34-266$ & 124 & 0,3200 & 92 & 156 \\
\hline & 950 & $34-266$ & 140 & 0,1700 & 81 & 199 \\
\hline \multirow[t]{2}{*}{$\overline{\mathrm{AST}}$} & 720 & $34-266$ & 192 & 1,4360 & 170 & 215 \\
\hline & 950 & $34-266$ & 205 & 1,1980 & 177 & 234 \\
\hline \multirow[t]{2}{*}{$\overline{\mathrm{AR}}$} & 720 & $34-266$ & 194 & 0,7460 & 176 & 214 \\
\hline & 950 & $34-266$ & 206 & 0,6200 & 181 & 231 \\
\hline \multirow[t]{2}{*}{ ANR } & 720 & $34-266$ & 191 & 0,7260 & 167 & 216 \\
\hline & 950 & $34-266$ & 205 & 0,5960 & 174 & 236 \\
\hline
\end{tabular}

(1)MS: matéria seca; AST: açúcares solúveis totais; AR: açúcares redutores; ANR: açúcares não-redutores. 
em menor tempo. Em situações com algum estresse, a planta em altitudes menores pode não ter tempo para a recuperação, ocorrendo prejuízo na formação final do fruto. Além disso, em altitudes menores, plantas de cafeeiro podem sofrer maior desgaste, por apresentarem menor período de formação dos frutos. Nessas circunstâncias, as plantas necessitam absorver nutrientes e produzir carboidratos em menor espaço de tempo para suprir as necessidades dos frutos.

O acúmulo de açúcares solúveis em frutos de cafeeiro iniciou-se na metade final do estádio de granação e encerrou-se na fase de maturação dos frutos (Figura 1 e Tabela 2). O aumento do conteúdo de açúcares solúveis em frutos no final do ciclo reprodutivo ocorre, principalmente, na polpa do fruto (Geromel et al., 2006) e está associado às mudanças morfo-fisiológicas relacionadas ao amadurecimento (Puschmann, 1975; Rena et al., 2001).

$\mathrm{O}$ acúmulo de AST, AR e ANR em frutos no estádio de granação na altitude de $720 \mathrm{~m}$ antecedeu o acúmulo destes compostos na altitude de $950 \mathrm{~m}$, como pode ser verificado ao se observar os valores de $\mathrm{PC}_{\text {mín }}$ e $\mathrm{PC}_{\text {máx }}$ na Tabela 2, evidenciando o efeito da altitude no acúmulo de açúcares na polpa.

O acúmulo de AST, AR e ANR nos frutos de cafeeiro iniciou-se próximo ao momento em que se estabilizou acúmulo de amido nos frutos (Tabela 2). É provável que a maior parte dos fotoassimilados drenados para os frutos no estádio de granação tenha sido direcionada primeiro para conversão em composto de reserva na semente e, só após completar este processo, tenha se iniciado o acúmulo de açúcares solúveis.
Os efeitos da altitude no ciclo reprodutivo, bem como no acúmulo de amido, AST, AR e ANR, estão relacionados, principalmente, a variações de temperaturas máximas entre as altitudes (Tabela 1). A temperatura possui influência direta sobre processos regulatórios da planta, e sob temperaturas menores a velocidade das reações enzimáticas é reduzida. Consequientemente, as taxas fotossintéticas e respiratórias também são restringidas (Larcher, 2000).

A exposição de um tecido-dreno a baixas temperaturas inibe as atividades que necessitam de energia metabólica e resulta na diminuição da velocidade do transporte em direção ao dreno. A atividade de um dreno está relacionada à presença e atividade das enzimas de clivagem da sacarose, à sacarose sintase e à invertase ácida, pois elas catalisam a primeira etapa de utilização da sacarose. Em menores temperaturas, a atividade dessas enzimas é restringida, portanto, diminuindo a velocidade do transporte de fotoassimilados no floema (Taiz \& Zeiger, 2004).

A concentração de amido nos 3ㅇ e 4 pares de folhas decresceu bruscamente no início do período reprodutivo, até 100 a 114 DAA, independentemente da altitude de cultivo (Figura 2). A queda na concentração de amido nas folhas nessa época está relacionada, principalmente, às demandas por fotoassimilados nos frutos, bem como às exigências para o crescimento vegetativo, o qual é intenso até meados de janeiro (Amaral et al., 2001).

Segundo Priestley (1962), as conversões de amido para açúcar ocorrem em ocasiões de crescimento vegetativo intenso, quando as reservas são usadas para suportar a atividade meristemática de ápices caulinares e também o crescimento de frutos. Após os 100 DAA,

Tabela 3. Acúmulo relativo ( $\mathrm{AR}_{\mathrm{e}}$, mg por fruto) de matéria seca (MS), amido, açúcares solúveis totais (AST), açúcares redutores (AR) e açúcares não-redutores (ANR), de acordo com o estádio de formação do fruto de cafeeiro implantado em duas altitudes.

\begin{tabular}{|c|c|c|c|c|c|c|c|c|c|c|c|}
\hline \multirow[t]{2}{*}{ Variável } & \multirow{2}{*}{$\begin{array}{l}\text { Altitude } \\
(\mathrm{m})\end{array}$} & \multicolumn{2}{|c|}{ Chumbinho } & \multicolumn{2}{|c|}{ Expansão rápida } & \multicolumn{2}{|c|}{ Crescimento suspenso } & \multicolumn{2}{|c|}{ Granação } & \multicolumn{2}{|c|}{ Maturação $^{(1)}$} \\
\hline & & $\mathrm{AR}_{\mathrm{e}}$ & $\%$ & $\mathrm{AR}_{\mathrm{e}}$ & $\%$ & $\mathrm{AR}_{\mathrm{e}}$ & $\%$ & $\mathrm{AR}_{\mathrm{e}}$ & $\%$ & $\mathrm{AR}_{\mathrm{e}}$ & $\%$ \\
\hline \multirow[t]{2}{*}{$\overline{\mathrm{MS}}$} & 720 & 32,8 & 5,56 & 186,3 & 31,58 & 10,15 & 1,72 & 312,9 & 53,10 & 47,34 & 8,03 \\
\hline & 950 & 18,6 & 3,15 & 118,1 & 20,00 & 15,52 & 2,63 & 431,8 & 73,12 & 6,49 & 1,10 \\
\hline \multirow[t]{2}{*}{ Amido } & 720 & 1,032 & 4,91 & 5,201 & 24,72 & 1,372 & 6,52 & 13,35 & 63,45 & 0,08 & 0,41 \\
\hline & 950 & 1,298 & 6,54 & 2,613 & 13,17 & 1,987 & 10,01 & 13,90 & 70,07 & 0,04 & 0,20 \\
\hline \multirow[t]{2}{*}{$\overline{\mathrm{AST}}$} & 720 & 3,078 & 4,59 & 0,034 & 0,05 & 0,020 & 0,03 & 53,71 & 80,13 & 10,184 & 15,20 \\
\hline & 950 & 1,346 & 1,96 & 0,033 & 0,05 & 0,074 & 0,11 & 66,81 & 97,44 & 0,301 & 0,44 \\
\hline \multirow[t]{2}{*}{$\mathrm{AR}$} & 720 & 2,161 & 7,06 & 0,003 & 0,01 & 0,002 & 0,01 & 24,146 & 78,90 & 4,292 & 14,03 \\
\hline & 950 & 0,776 & 2,46 & 0,005 & 0,02 & 0,015 & 0,05 & 30,685 & 97,18 & 0,093 & 0,30 \\
\hline \multirow[t]{2}{*}{$\overline{\mathrm{ANR}}$} & 720 & 0,918 & 2,52 & 0,040 & 0,11 & 0,021 & 0,06 & 29,48 & 80,98 & 5,947 & 16,13 \\
\hline & 950 & 0,564 & 1,52 & 0,034 & 0,09 & 0,067 & 0,18 & 36,11 & 97,63 & 0,211 & 0,57 \\
\hline
\end{tabular}

${ }^{(1)}$ Considerou-se como maturação o período após o início da estabilização no acúmulo de MS no fruto, embora as mudanças na coloração da casca correspondentes à maturação tenham se iniciado antes. 
verificou-se que a concentração de amido em folhas se elevou novamente na altitude de $720 \mathrm{~m}$, ao passo que, na altitude de $950 \mathrm{~m}$, a concentração desse composto manteve-se baixa, apresentando pequena tendência de aumento no final do ciclo reprodutivo. É possível que a maior concentração de amido em folhas, na altitude de $720 \mathrm{~m}$, esteja relacionada à menor produção de frutos. Uma menor produção de frutos pode ter resultado em menor força de dreno (Taiz \& Zeiger, 2004) ocorrendo, com isto, balanço positivo de fotoassimilados nas folhas, que podem ter sido armazenados na forma de amido (Marenco \& Lopes, 2005). Apesar disso, Janardhan et al. (1971) encontraram níveis elevados de amido, em ramos com carga elevada, sendo improvável que as concentrações de amido nas folhas e ramos esteja apenas relacionada à formação dos frutos.
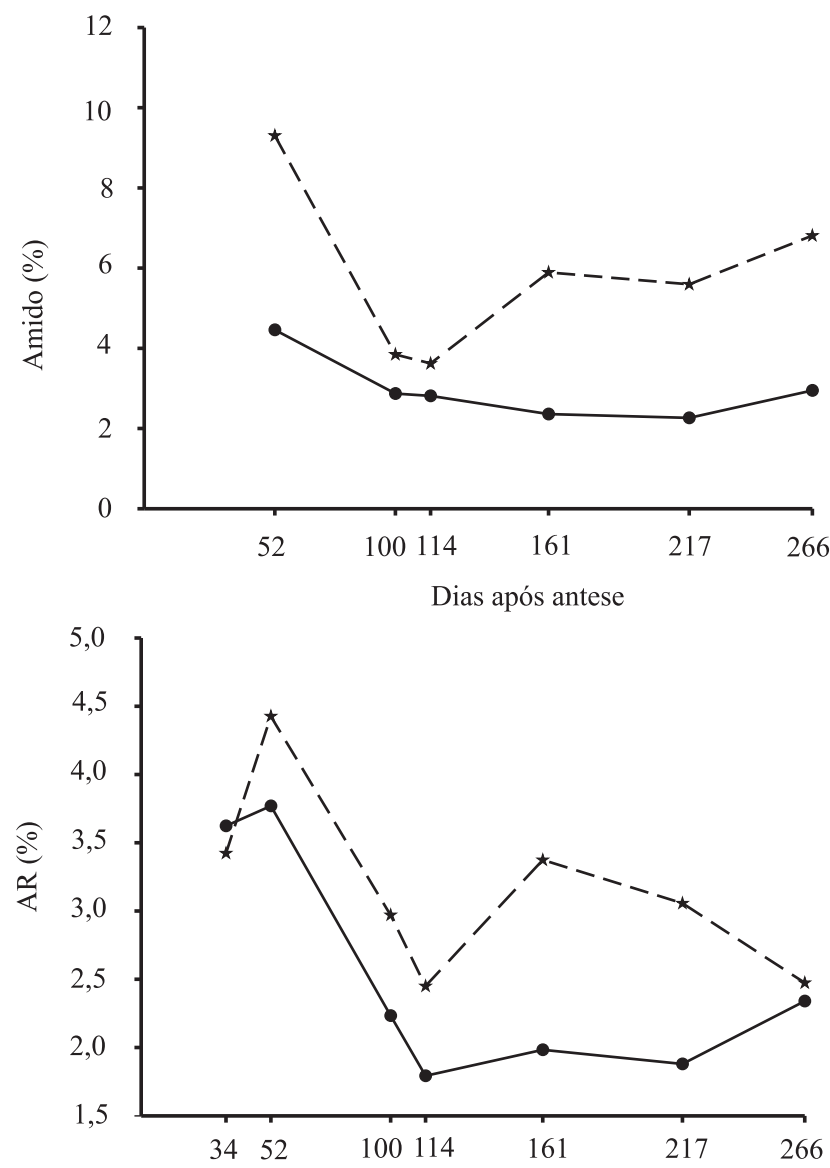

Dias após antese
As concentrações de AST e AR, conforme ocorreu com o conteúdo de amido, também decresceram bruscamente no início do período reprodutivo, até em torno dos 114 DAA (Figura 2). É provável que a maior parte do açúcar sintetizado neste período tenha sido mobilizada para o crescimento vegetativo e para a frutificação. Com relação ao ANR (Figura 2), observouse queda nas folhas, no início do ciclo reprodutivo, apenas na altitude de $950 \mathrm{~m}$, enquanto a $720 \mathrm{~m}$ de altitude, a concentração de ANR nas folhas se elevou dos 52 aos 90 DAA. É provável que a degradação do amido, que estava em maior concentração inicial na altitude de $720 \mathrm{~m}$, tenha resultado em maior síntese de sacarose.

Ao final do ciclo, observa-se que a concentração de ANR se elevou, superando as suas concentrações no início do ciclo, ao contrário do que ocorreu para AST e AR (Figura 2). Os frutos no final do ciclo reprodutivo
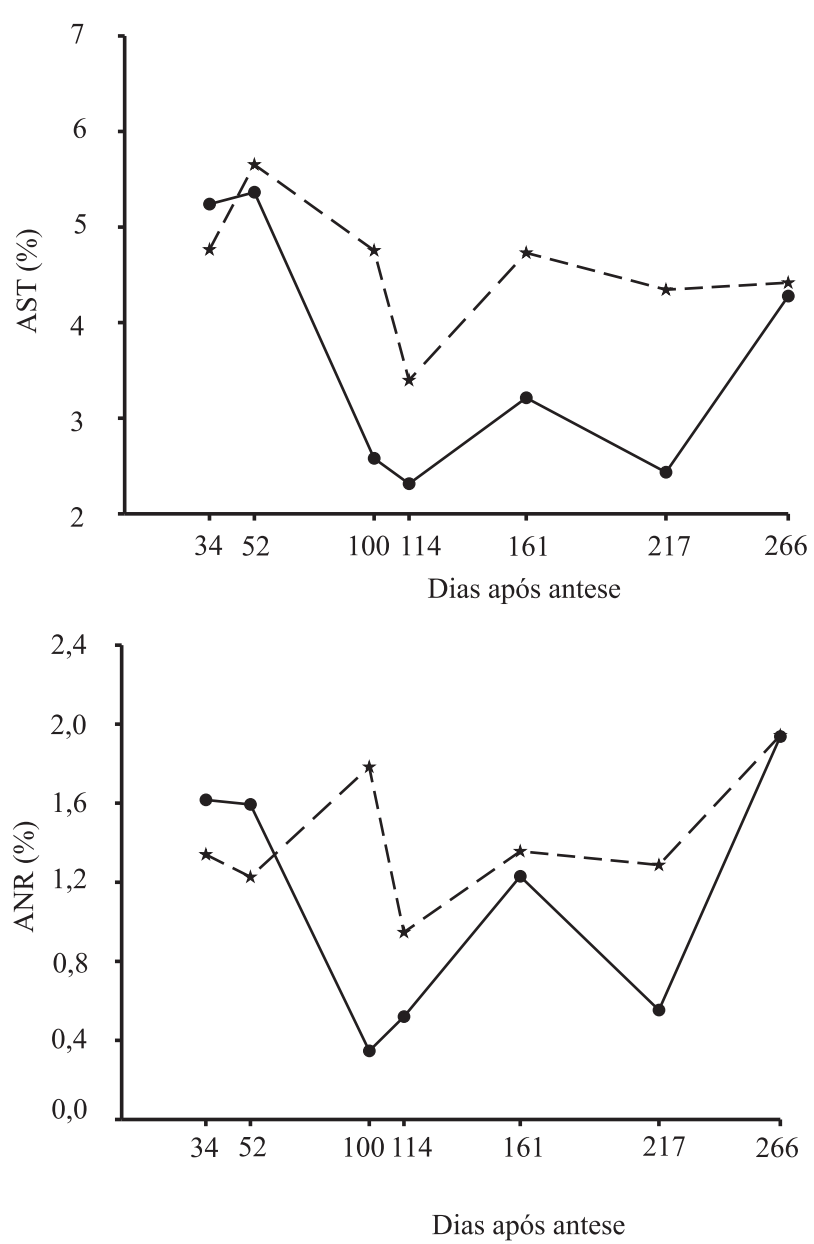

Figura 2. Concentração de amido, açúcares solúveis totais (AST), açúcares redutores (AR), açúcares não-redutores (ANR) em base da matéria seca de folhas de cafeeiro implantado em duas altitudes, de acordo com o tempo decorrido após a antese. 
deixam, gradativamente, de serem drenos prioritários (Rena \& Carvalho, 2003) e a taxa de crescimento vegetativo tende também a diminuir de acordo com o declínio na temperatura (Amaral et al., 2001) e, em conseqüência, o transporte de ANR diminui, podendo assim elevar sua concentração na fonte (folha).

O estádio de expansão rápida do fruto (Figura 1) parece ser o período mais crítico da concentração de carboidratos nas folhas de cafeeiro (Figura 2). De acordo com Wormer \& Ebagole (1965) e Patel (1970), quanto mais intensa a frutificação, menor o teor de amido nos ramos, podendo até ocorrer o esgotamento total das reservas na fase de expansão rápida dos frutos. No entanto, a fase de maior demanda de fotoassimilados pelos frutos é o estádio de granação (Tabela 3), que ocorreu após os 114 DAA. O estádio de expansão rápida é também o período de maior crescimento vegetativo (Amaral et al., 2001), atingindo-se no estádio de granação área foliar fotossinteticamente ativa superior à do início do ciclo reprodutivo (Castro, 2002). Como a produção de fotoassimilados pela planta depende não só da taxa fotossintética $\left(\mu \mathrm{mol} \mathrm{CO}_{2} \mathrm{~m}^{-2} \mathrm{~s}^{-1}\right)$, mas também da área foliar, é possível que na época de granação haja maior número de folhas (maior área foliar) para suprir um mesmo número de frutos. Desta forma, haveria menor esgotamento das reservas orgânicas de cada folha, podendo em alguns casos haver aumento do conteúdo de compostos de reservas (Figura 2).

As práticas culturais adequadas no início do período reprodutivo, principalmente relacionadas à nutrição mineral, são importantes para proporcionar rápido aumento da área foliar das plantas e, posteriormente, garantir granação adequada dos frutos do cafeeiro. Por sua vez, se os frutos forem drenos prioritários, e se não houver aumento significativo da área foliar até o final do estádio de expansão rápida, pode haver esgotamento das plantas no período de maior demanda (granação) e, desta forma, intensificação do fenômeno da bienalidade de produção do cafeeiro. É importante ressaltar que as reservas foliares de amido são apenas um indicativo do status metabólico da planta, pois, por si só, não possuem capacidade de sustentar o crescimento vegetativo e o enchimento de grãos, processos altamente dependentes da fotossíntese corrente (Carvalho et al., 1993).

\section{Conclusões}

1. A elevação da altitude de cultivo do cafeeiro influencia a alocação de fotoassimilados em frutos e folhas de cafeeiro.

2. Na altitude de $720 \mathrm{~m}$ há antecipação no acúmulo de amido, açúcares solúveis totais, açúcares redutores e açúcares não-redutores em frutos de cafeeiro.

\section{Agradecimentos}

À Universidade Federal de Viçosa, ao CNPq e ao Consórcio Brasileiro de Pesquisa e Desenvolvimento do Café, pelo apoio financeiro.

\section{Referências}

AMARAL, J.A.T.; MATTA, F.M. da; RENA, A.B. Effects of fruiting on the growth of Arabica coffee trees as related to carbohydrate and nitrogen status and to nitrate reductase activity. Revista Brasileira de Fisiologia Vegetal, v.13, p.66-74, 2001.

CAMARGO, A.P.; CAMARGO, M.B.P. de. Definição e esquematização das fases fenológicas do cafeeiro arábica nas condições tropicais do Brasil. Bragantia, v.60, p.65-68, 2001.

CANNEL, M.G.R. Seasonal patterns of growth and development of arabica coffee in Kenya. Part IV: effects of seasonal differences in rainfall on bean size. Kenya Coffee, v.36, p.175-180, 1971.

CARVALHO, C.H.S. de; RENA, A.B.; PEREIRA, A.A.; CORDEIRO, A.T. Relação entre produção, teores de N, P, K, Ca, $\mathrm{Mg}$, amido e a seca de ramos do Catimor (Coffea arabica L.). Pesquisa Agropecuária Brasileira, v.28, p.665-673, 1993.

CASTRO, A.M. de. Efeito de desfrutificações seqüienciais sobre o crescimento e produção de cafeeiro arábico. 2002. 97p. Tese (Doutorado) - Universidade Federal de Viçosa, Viçosa.

COOMBE, B.G. The development of fleshy fruits. Annual Review of Plant Physiology, v.27, p.507-528, 1976.

GEROMEL, C.; FERREIRA, L.P.; GUERREIRO, S.M.C.; CAVALARI, A.A.; POT, D.; PEREIRA, L.F.; LOREY, T.; VIEIRA, L.G.E.; MAZZAFERA, P.; MARRACCINI, P. Biochemical and genomic analysis of sucrose metabolism during coffee (Coffea arabica) fruit development. Journal of Experimental Botany, v.57, p.3243-3258, 2006.

GIORGINE, J.F.; CAMPOS, C.A.S.P. Changes in the content of soluble sugars and starch synthesis and degradation during germination and seedling growth of Coffea arabica L. Revista Brasileira de Fisiologia Vegetal, v.4, p.11-15, 1992.

GUIMARÃES, P.T.G.; GARCIA, A.W.R.; ALVAREZ VENEGAS, V.H.; PREZOTTI, L.C.; VIANA, A.S.; MIGUEL, A.E.; MALAVOLTA, E.; CORRÊA, J.B., LOPES, A.S.; NOGUEIRA, F.D.; MONTEIRO, A.V.C. Cafeeiro. In: RIBEIRO, A.C.; GUIMARÃES, P.T.G.; ALVAREZ VENEGAS, V.H. (Ed.). 
Recomendações para o uso de corretivos e fertilizantes em Minas Gerais: 5. Aproximação. Viçosa: Comissão de Fertilidade do Solo do Estado de Minas Gerais, 1999. p.289-302.

HODGE, J.E.; HODFREITER, B.R. Determination of reducing sugars and carbohydrates. In: WILSTER, R.L.; WOLFROM, M.L. (Ed.). Methods in carbohydrate chemistry. New York: Academic Press, 1962. p.390-394.

JANARDHAN, K.V.; GOPAL N.H.; RAMAIAH, P.K. Carbohydrate reserves in relation to vegetative growth, flower bud formation and crop levels in arabica coffee. Indian Coffee, p.145$148,1971$.

LARCHER, W. Ecofisiologia vegetal. São Carlos: RiMa, 2000. $531 \mathrm{p}$.

LAVIOLA, B.G. Alocação de fotoassimilados e nutrientes em folhas e frutos de cafeeiro em diferentes altitudes de cultivo. 2007. 136p. Tese (Doutorado) - Universidade Federal de Viçosa, Viçosa.

LAVIOLA, B.G.; MARTINEZ, H.E.P.; SOUZA, R.B. de; ALVAREZ VENEGAS, V.H. Dinâmica de cálcio e magnésio em folhas e frutos de cafeeiro arábico em três níveis de adubação. Revista Brasileira de Ciência do Solo, v.31, p.319-329, 2007.

LEON, J.; FOURNIER, L. Crecimiento y desarrollo del fruto de Coffea arabica L. Turrialba, v.12, p.65-74, 1962.

MARENCO, R.A.; LOPES, N.F. Fisiologia vegetal: fotossíntese, respiração, relações hídricas e nutrição mineral. Viçosa: UFV, 2005. $451 \mathrm{p}$.

MATIELLO, J.B.; SANTINATO, R.; GARCIA, A.W.R.; ALMEIDA, S.R.; FERNANDES, D.R. Cultura de café no Brasil: novo manual de recomendações. Rio de Janeiro: MAPA/PROCAFE, 2005. 438p.

McCREADY, R.M.; GUGGOLZ, J.; SILVEIRA, V.; OWENS, H.S. Determination of starch and amylose in vegetables: application to peas. Analytical Chemistry, v.22, p.1156-1158, 1950.
NELSON, N.A. A photometric adaptation of the Somogy method for the determination of glucose. Journal of Biological Chemistry, n.153, p.375-380, 1944.

PATEL, R.Z. A note on the seasonal variations in starch content of different parts of arabica coffee trees. East African Agricultural and Forestry Journal, v.36, p.1-6, 1970.

PRIESTLEY, C.A. Carbohydrate resources within the perennial plant. Commonwealth Agricultural Bureaux, Farnham Royal, 1962. v.27. $116 \mathrm{p}$.

PUSCHMANN, R. Características bioquímicas do fruto do cafeeiro (Coffea arabica L.) durante a maturação. 1975. 35p. Dissertação (Mestrado) - Universidade Federal de Viçosa, Viçosa.

RENA, A.B.; BARROS, R.S.; MAESTRI, M. Desenvolvimento reprodutivo do cafeeiro. In: ZAMBOLIM, L. (Org.). Tecnologias de produção de café com qualidade. Viçosa: UFV, 2001. p.101-128.

RENA, A.B.; CARVALHO, C.H.S. Causas abióticas da seca de ramos e morte de raízes em café. In: ZAMBOLIN, L. (Org.). Produção integrada de café. Viçosa: UFV, 2003. p.197-222.

RENA, A.B.; MAESTRI, M. Fisiologia do cafeeiro. Informe Agropecuário, v.11, p.26-40, 1985.

RENA, A.B.; NACIF, A.P.; GONTIJO, P. de T.; PEREIRA, A.A. Fisiologia do cafeeiro em plantios adensados. In: SIMPÓSIO INTERNACIONAL SOBRE CAFÉ ADENSADO, 1994, Londrina. Anais. Londrina: Instituto Agronômico do Paraná, 1996. p.73-85.

SOMOGY, M. Notes of sugar determination. Journal of Biological Chemistry, v.195, p.19-23, 1952.

TAIZ, L.; ZEIGER, E. Fisiologia vegetal. 3.ed. Porto Alegre: Artmed, 2004. 720p.

VENEGAS, J.G.; HARRIS, R.S.; SIMON, B.A. A comprehensive equation for the pulmonary pressure-volume curve. The American Physiological Society, v.84, p.389-395, 1998.

WORMER, T.M.; EBAGOLE, H.E. Visual scoring of starch in Coffea arabica L. II. Starch in bearing and non-bearing branches. Experimental Agriculture, v.1, p.41-53, 1965. 